\title{
A new body mass estimation of Brachiosaurus brancai Janensch, 1914 mounted and exhibited at the Museum of Natural History (Berlin, Germany)
}

\author{
Hanns-Christian Gunga*,1, Tim Suthau ${ }^{2}$, Anke Bellmann ${ }^{2}$, Stefan Stoinski², Andreas Friedrich ${ }^{2}$, \\ Tobias Trippel ${ }^{1}$, Karl Kirsch ${ }^{1}$ and Olaf Hellwich ${ }^{2}$ \\ ${ }^{1}$ Department of Physiology, Center of Space Medicine Berlin, Charité Universitätsmedizin Berlin, Campus Benjamin Franklin, Arminallee 22, \\ 14195 Berlin, Germany. E-mail: hanns-christian.gunga@charite.de \\ ${ }^{2}$ Computer Vision and Remote Sensing, TU Berlin, Franklinstraße 28/29, 10587 Berlin, Germany.
}

Received 17 July 2007

Accepted 10 September 2007

Published 15 February 2008

\section{Key Words}

Dinosauria

Sauropoda

paleophysiology

body mass estimation

specific tissue density

paleoecology

\begin{abstract}
Body mass and surface areas are important in several aspects for an organism living today. Therefore, mass and surface determinations for extinct dinosaurs could be important for paleo-biological aspects as well. Based on photogrammetrical measurement the body mass and body surface area of the Late Jurassic Brachiosaurus brancai Janensch, 1914 from Tendaguru (East Africa), a skeleton mounted and exhibited at the Museum of Natural History in Berlin (Germany), has been re-evaluated. We determined for a slim type of 3D reconstruction of Brachiosaurus brancai a total volume of $47.9 \mathrm{~m}^{3}$ which represents, assuming a mean tissue density of $0.8 \mathrm{~kg}$ per $1,000 \mathrm{~cm}^{3}$, a total body mass of $38,000 \mathrm{~kg}$. The volume distributions from the head to the tail were as follows: $0.2 \mathrm{~m}^{3}$ for the head, neck $7.3 \mathrm{~m}^{3}$, fore limbs $2.9 \mathrm{~m}^{3}$, hind limbs $2.6 \mathrm{~m}^{3}$, thoracic-abdominal cavity $32.4 \mathrm{~m}^{3}$, tail $2.2 \mathrm{~m}^{3}$. The total body surface area was calculated to be $119.1 \mathrm{~m}^{2}$, specifically $1.5 \mathrm{~m}^{2}$ for the head, $26 \mathrm{~m}^{2}$ neck, fore limbs $18.8 \mathrm{~m}^{2}$, hind limbs $16.4 \mathrm{~m}^{2}, 44.2 \mathrm{~m}^{2}$ thoracic-abdominal cavity, and finally the tail $12.2 \mathrm{~m}^{2}$. Finally, allometric equations were used to estimate presumable organ sizes of this extinct dinosaur and to test whether their dimensions really fit into the thoracic and abdominal cavity of Brachiosaurus brancai if a slim body shape of this sauropod is assumed.
\end{abstract}

\section{Introduction}

Numerous studies have shown that body mass and body surface are major factors in an animal's life history and daily requirements. Unfortunately, the literature differs considerably in setting estimates of body mass for dinosaurs (Peczkis 1994). Therefore, we have introduced classical photogrammetry for assessing body mass and surface area of extinct organisms such as Brachiosaurus brancai Janensch, 1914 (Gunga et al. 1995). The highly disparate estimates to be found in the literature are mainly due to different methods for mass estimations, such as bone circumferences and models, and the main advantages and disadvantages of some of these methods have been intensively discussed before (Colbert 1962;
Lambert 1980; Schmidt-Nielsen 1984, 1997; Anderson et al. 1985; Haubold 1990; Withers 1992; Carroll 1993; Gunga et al. 1999; Henderson 1999; Seebacher 2001; Motani 2001; Christiansen \& Fariña 2004). However, recently it was pointed out that extensive postcranial skeletal pneumaticity in sauropods has to be taken in account, leading to a substantial mass reduction (Wedel 2003, 2005). Based on this study we assumed a mean tissue density of only $0.8 \mathrm{~kg}$ per $1,000 \mathrm{~cm}^{3}$, much lower than previously assumed. Nevertheless, we would like to stress the point that such a tissue density of 0.8 given by Wedel $(2003,2005)$ is the lower estimate for tissue density for sauropods, but not necessarily exactly the density to be assumed and it might well be that the sauropod tissue density was probably somewhere in

\footnotetext{
* Corresponding author
} 
between this value and the value of 1 as originally assumed.

Therefore, it was the aim of the present study (1) to re-evaluate our own previously published data on the body and surface areas of the Late Jurassic Brachiosaurus brancai from Tendaguru/Tanzania (East Africa) (Gunga et al. 1995, 1999), mounted and exhibited at the Museum of Natural History (Berlin, Germany). Furthermore, we tested (2) whether the main organs of this extinct dinosaur such as skin, lung, heart, gastrointestinal tract, and muscular system, derived from the body mass and calculated according scaling equations, really fit into the anatomical dimensions of the thoracic and abdominal cavity of Brachiosaurus brancai if a slim body shape of this sauropod is assumed.

\section{Methods}

The study was performed on Brachiosaurus brancai (skeleton II) mounted and exhibited at the Museum of Natural History in Berlin (Germany). The skeleton is a composite since the tail originates from another individual of the same species and similar size found in the Upper Saurian Beds. In addition, skeletal remains of Brachiosaurus brancai excavated in different sites in the surroundings of the Tendaguru hill were used for the mounting, partly original and partly modelled. The presacral vertebral column (cervical, dorsal) and the skull have been replaced by plaster copies modelled from originals. The right shoulder blade, four ribs, and some bones of the left forefoot have been modelled in plaster according to counterparts on the other body side. Some missing elements were replaced by bones belonging to individuals of the same size, such as the right ilium, the right ischium, and left lower leg. Other missing items have been replaced by originals (e.g. left femur) or copies of bones from different-sized animals (i.e. sacrum, most hindfoot bones). At the very end of the tail four small pieces were added. Like the missing first caudal vertebra, most of the haemapophyses (chevrons) are plaster imitations (Janensch 1950).

A detailed description of the classical photogrammetrical method and the mathematical formulas which we applied can be omitted here because these procedures were described earlier (Gunga et al. 1995, 1999). Briefly, several pictures from the 3D reconstruction of the mounted skeleton of Brachiosaurus brancai were printed (Fig. 1, side view) and served as scaled masters for drawing the shape of the dinosaur. Here, (1) the shape of the extremities including musculature followed that of an elephant leg, (2) the shape of the thorax followed the anatomical limitations given mainly by the skeleton (rips and vertebrae) assuming a minimal fat and muscular integument, and (3) the neck and tail we assumed to be elliptical in shape, instead of circular shape, as in the previous study (Gunga et al. 1995). Usually, the reconstructed shapes were subdivided into geometrical primitives like cylinders, frustums and spherical horns to compute the surface as well as the volume. In the present study, to improve the modelling of the surface instead of geometric primitives rotational solids were applied. The basis for CAD based modelling is likewise the $3 \mathrm{D}$ reconstruction of the dinosaur skeletons. The dinosaur was subdivided into constructive rotational solids. These solids ensure an enhanced accommodation to approximate the real shapes, also allowing complex changes of models with reasonable effort. Several rotational solids were diluted and the volume was computed accordingly. Using CAD-functionalities like extrusion and rotation enables modelling of more complex body geometries. However, partially substantial restrictions exist. It is possible to extrude any surface area along a freely selectable path. Along this extrusion the surface remains however constant, thus the form of the end face is equal to the front. The variability of rotational solids is limited by the radial symmetry regarding the rotation axis. Combinations of these solids by using Boolean operators as union, subtraction and intersection leave a multiplicity of high-complex body forms to realize. Additionally, the 3D-viewing options (wire frames, shaded and render views) give the opportunity to evaluate the finished model on a clearly more realistic way. The shape of the body model can, just as the several distances from the skeleton, be regarded and verified from each direction. With consideration of these improvements an iterative modeling proved as the most meaningful solution in contrast to the former type of modeling. A further improvement of the modelling results from use of so called NURBS (Non uniform rationally b-Splines). Nurbs is a mathematical model for generating and representing curves and surfaces. Nurbs surfaces are three-dimensional free form shapes with no limitation on certain mathematical body geometry. They provide realistic smooth body surfaces and they can be evaluated by numerically stable mathematical algorithms. The form of nurbs curves and surfaces is defined by its order, the position and weight of its control points and a knot vector. In practice mainly the control points are interesting. Moving the control points, changes intuitively the appearance of the curve. Thus, the former named iterative adjustments of the body models were achieved directly by moving the control points of the surfaces.

For the body mass estimation, here in contrast to the previous studies (Gunga et al. 1995, 1999), we assumed a tissue density of $0.8 \mathrm{~kg}$ per $1,000 \mathrm{~cm}^{3}$ instead of $1.0 \mathrm{~kg}$ per $1,000 \mathrm{~cm}^{3}$.

Finally, anatomical and physiological parameters were calculated after equations from Schmidt-Nielsen (1984), Anderson et al. (1979), Calder (1984, 1996) assuming a high metabolic rate comparable to mammals, and equating after Schmidt-Nielsen (1984) 11 oxygen consumption during oxydative metabolism (at $0{ }^{\circ} \mathrm{C}, 760 \mathrm{~mm} \mathrm{Hg}$ ) with $20,083 \mathrm{~kJ}$. Allometric equations from mammals were used because recent data from Sander (2000), Sander \& Tückmantel (2003), and Erickson (2005) indicate that whole-organism growth rates for dinosaurs were faster than those of living reptiles of equivalent size, especially in juvenile dinosaurs such as the exhibited specimen in the $\mathrm{Mu}$ seum of Natural History in Berlin. That is why we did not use allometric functions derived from reptiles. Furthermore, we did not use allometric functions from birds because here - actually - a data base of specimens with a comparable body mass really does not exist. In mammals - at least - data from the megaherbivores such as the African elephant are available and have been studied intensively.

\section{Results}

The main results are summerized in Fig. 1, Fig. 2A, B as well as in Table 1. Fig. 2A shows a side view (upper panel) and Fig. 2B a top view (lower panel) of the assumed body shape of Brachiosaurus brancai. The calculated center of gravity is marked with a cross in Fig. 2A (upper panel). We determined for this slim type of 3D reconstruction of Brachiosaurus brancai a total volume of $47.6 \mathrm{~m}^{3}$ which represents, if we assume of mean tissue density of $0.8 \mathrm{~kg}$ per $1,000 \mathrm{~cm}^{3}$, a total body mass of $38,000 \mathrm{~kg}$. In detail, the volume distributions from the head to the tail were as follows: $0.2 \mathrm{~m}^{3}$ for the head, neck $7.3 \mathrm{~m}^{3}$, fore limbs $2.9 \mathrm{~m}^{3}$, hind limbs $2.6 \mathrm{~m}^{3}$, thoracic-abdominal cavity $32.4 \mathrm{~m}^{3}$, tail $2.2 \mathrm{~m}^{3}$. The total body surface area was calculated to be $119.1 \mathrm{~m}^{2}$, specifically $1.5 \mathrm{~m}^{2}$ for the head, $26 \mathrm{~m}^{2}$ neck, fore limbs $18.8 \mathrm{~m}^{2}$, hind limbs $16.4 \mathrm{~m}^{2}, 44.2 \mathrm{~m}^{2}$ thor- 


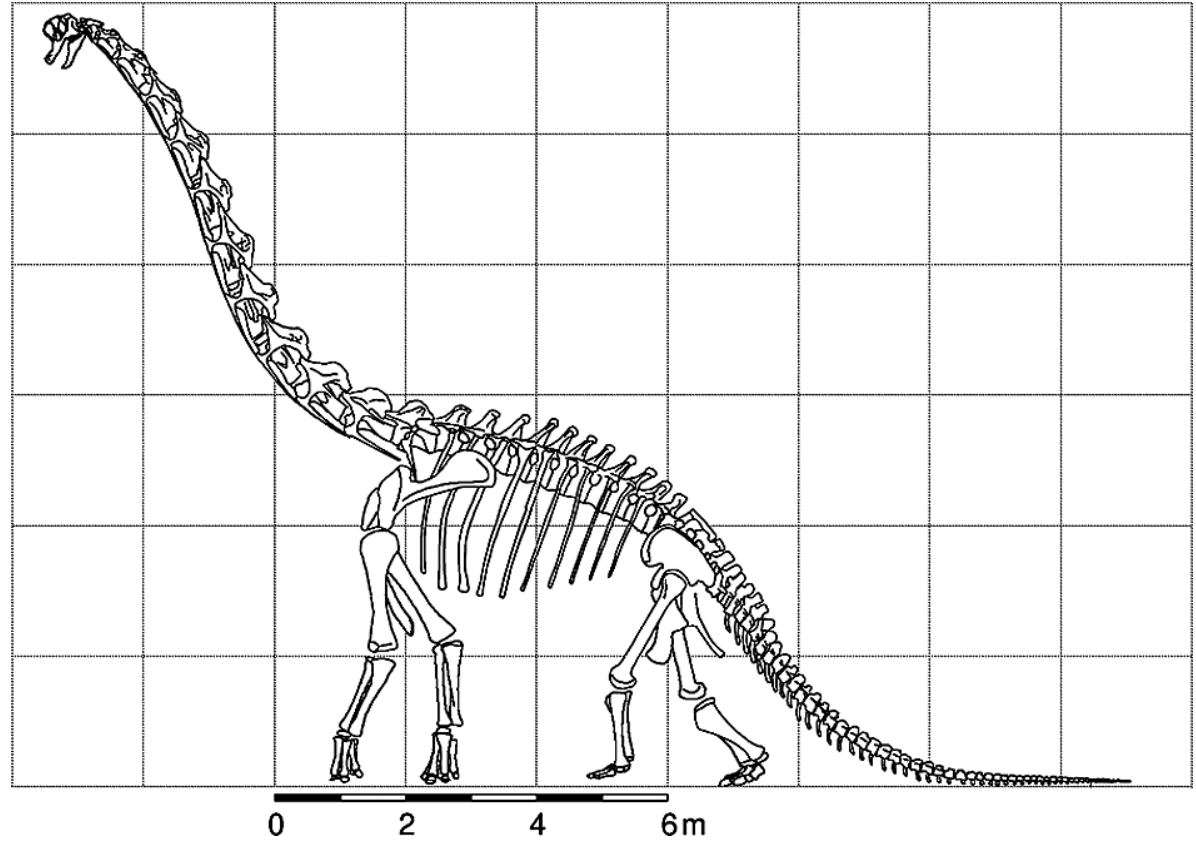

Figure 1. Results of evaluating the laser scanner image of the skeleton of Brachiosaurus brancai mounted and exhibited at the Museum of Natural History in Berlin (Germany) (side view). acic-abdominal cavity, and finally the tail $12.2 \mathrm{~m}^{2}$. The major organ and organ system sizes, derived from the body mass estimations by allometric functions such as skeleton and muscle mass, basal metabolic rate, gastrointestinal tract, are summarized in Table 1.

\section{Discussion}

If we compare the present data of Brachiosaurus brancai with our own previously published data then the body surface estimations by photogrammetry are in the
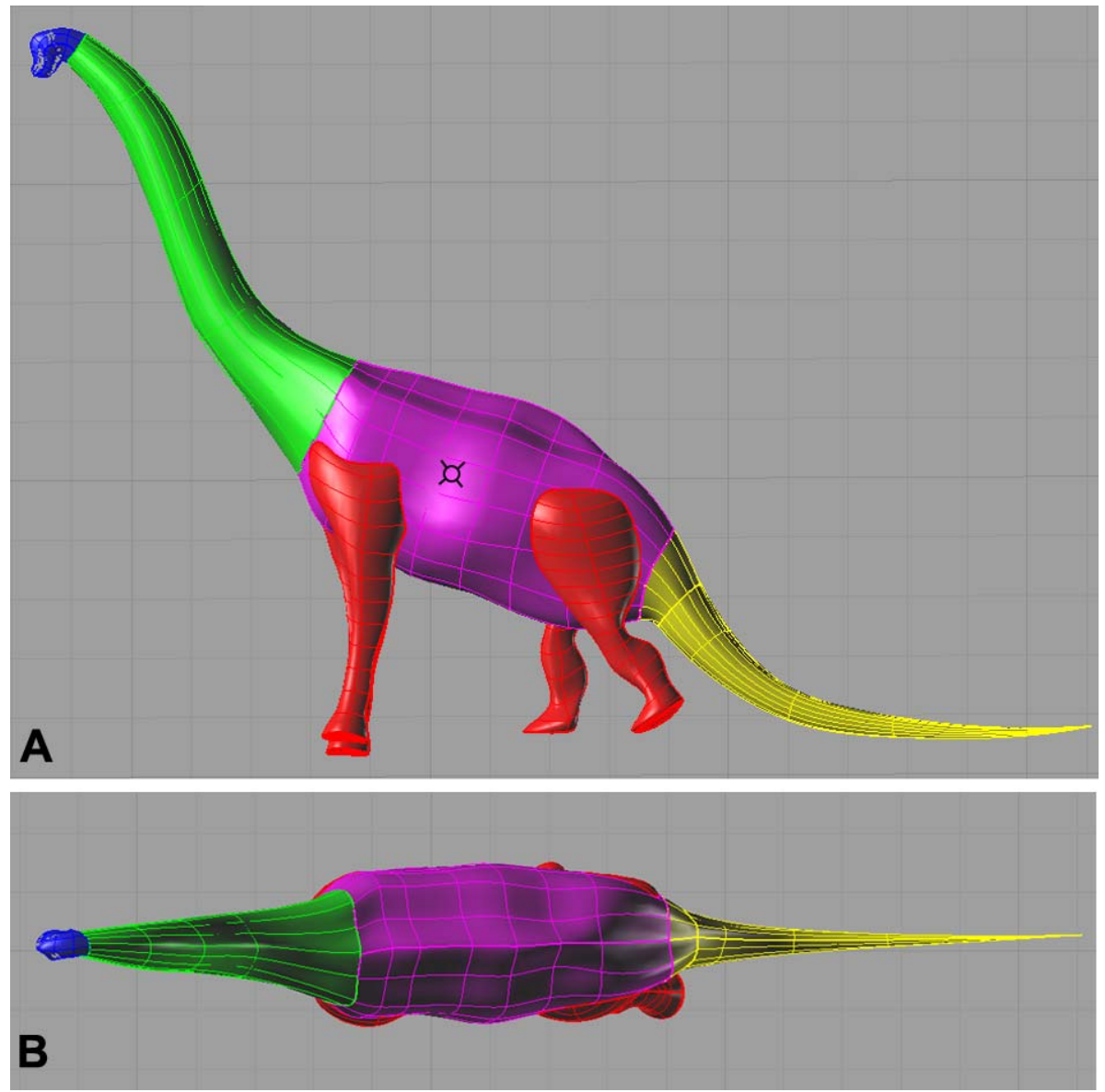

Figure 2.3D slim version of reconstruction of Brachiosaurus brancai mounted and exhibited at the Museum of Natural History in Berlin (Germany). A. Side view, upper panel; B. Top view, lower panel. The cross in the figure of upper panel indicates the calculated center of gravity. This figure is available in colour online at museum-fossilrecord.wiley-vch.de 
Table 1. Body mass, body surface and presumable physiological data of a slim reconstruction of Brachiosaurus brancai mounted and exhibited at the Museum of Natural History (Berlin, Germany). Anatomical and physiological parameters were calculated after equations from Bronstein and Semendjajew (1985), Schmidt-Nielsen (1984), Anderson et al. (1979), Calder (1984), Calder (1996) and equating after Schmidt-Nielsen (1984) 11 oxygen consumption during oxydative metabolism (at $0{ }^{\circ} \mathrm{C}, 760 \mathrm{~mm} \mathrm{Hg}$ ) with $20,083 \mathrm{~kJ}$, and assuming that $1,000 \mathrm{~cm}^{3}$ of tissue mass has a specific weight of $0.8 \mathrm{~kg}$ according to Wedel (2005).

\begin{tabular}{|c|c|c|}
\hline Anatomical and physiological parameters & Allometric functions & Brachiosaurus brancai \\
\hline Body volume $\left[\mathrm{m}^{3}\right]$ & & 47.9 \\
\hline Body mass $(\mathrm{Mb})[\mathrm{kg}]$ & & 38,000 \\
\hline Body surface area $\left[\mathrm{m}^{2}\right]$ & & 119.1 \\
\hline Skeleton $[\mathrm{kg}]$ & $\left(0.0608 \mathrm{Mb}^{1.083}\right)$ & 5,544 \\
\hline Integument [kg] & $\left(0.106 \mathrm{Mb}^{0.94}\right)$ & 2,140 \\
\hline Muscle mass $[\mathrm{kg}]$ & $\left(0.45 \mathrm{Mb}^{1.0}\right)$ & 17,100 \\
\hline Lung mass $[\mathrm{kg}]$ & $\left(0.011 \mathrm{Mb}^{0.99}\right)$ & 376 \\
\hline Lung volume [l] & $\left(0.063 \mathrm{Mb}^{1.02}\right)$ & 2,956 \\
\hline Tidal volume [l] & $\left(0.0062 \mathrm{Mb}^{1.01}\right)$ & 261 \\
\hline Respiration frequency $\left[\mathrm{min}^{-1}\right]$ & $\left(53.5 \mathrm{Mb}^{-0.26}\right)$ & 3.5 \\
\hline $\mathrm{O}_{2}$ consumption $\left[\mathrm{l} \mathrm{h}^{-1}\right]$ & $\left(0.676 \mathrm{Mb}^{0.75}\right)$ & 206 \\
\hline $\mathrm{O}_{2}$ consumption $\left[\mathrm{h}^{-1} \mathrm{~kg}^{-1}\right]$ & $\left(0.676 \mathrm{Mb}^{-0.25}\right)$ & 0.05 \\
\hline Basal metabolic rate $\left[\mathrm{kJ}(24 \mathrm{hrs})^{-1}\right]$ & & 915,785 \\
\hline Respiration frequency $\left[\mathrm{min}^{-1}\right]$ & $\left(53.5 \mathrm{Mb}^{-0.26}\right)$ & 3.5 \\
\hline Blood volume [l] & $\left(0.055 \mathrm{Mb}^{0.99}\right)$ & 1,881 \\
\hline Heart mass [kg] & $\left(0.0058 \mathrm{Mb}^{0.99}\right)$ & 198 \\
\hline Heart rate $\left[\mathrm{min}^{-1}\right]$ & $\left(241 \mathrm{Mb}^{-0.25}\right)$ & 17.3 \\
\hline Kidney mass [kg] & $\left(0.007 \mathrm{Mb}^{0.85}\right)$ & 55 \\
\hline Liver mass $[\mathrm{kg}]$ & $\left(0.033 \mathrm{Mb}^{0.87}\right)$ & 318 \\
\hline Spleen mass & $\left(0.003 \mathrm{Mb}^{1.02}\right)$ & 141 \\
\hline Gut mass [kg] & $\left(0.053 \mathrm{Mb}^{1.02}\right)$ & 2,487 \\
\hline
\end{tabular}

same order of magnitude, i.e. $119.1 \mathrm{~m}^{2}$ vs. $138.9 \mathrm{~m}^{2}$ (Gunga et al. 1995, 1999). The main differences between the two reconstructions lie in the volume and mass estimations, i.e. $47.9 \mathrm{~m}^{3}$ vs. $74.4 \mathrm{~m}^{3}$ and $38,000 \mathrm{~kg}$ vs. $74,400 \mathrm{~kg}$, respectively. The different volume/mass estimations are mainly due (1) to a much more slim reconstruction of the thoracic-abdominal cavity and (2) the assumption of a much lower tissue density. Whereas in the previous reconstruction (Gunga et al. 1995, 1999) for the thoracic-abdominal cavity a volume of $55.12 \mathrm{~m}^{3}$ was determined, in the present slim version this segment accounts only for of $32.4 \mathrm{~m}^{3}$. The main other segments show a similar percentage reduction: for the neck $7.3 \mathrm{~m}^{3}$ vs. $11.2 \mathrm{~m}^{3}$ previously determined, and for the tail $2.2 \mathrm{~m}^{3}$ vs. $3.28 \mathrm{~m}^{3}$, respectively. For the substantial mass decrease from $74,400 \mathrm{~kg}$ to $38,000 \mathrm{~kg}$ accounts that (1) we assumed now a mean tissue density of $0.8 \mathrm{~kg}$ per $1,000 \mathrm{~cm}^{3}$ which per se gives a mass reduction by $20 \%$ according to the recent data on pneumaticity in sauropods (Wedel 2003, 2005) and (2) an improved surface modelling because we applied instead of geometric primitives rotational solids.

Now, we will discuss in detail the anatomical and physiological results of the study. The volume distribution indicates that $68 \%$ of the mass of Brachiosaurus brancai is located particularly in the thoracic-abdominal cavity (Fig. 2). Furthermore, in contrast to prosau- ropods such as Plateosaurus (Gunga et al. 2007), we see in Brachiosaurus brancai, a very long, massive neck with a volume of about $7.3 \mathrm{~m}^{3}$ which represents $15 \%$ of the body mass, and at least $\sim 5 \%$ of the total body mass are located in the tail. The center of gravity (marked with a cross in Fig. 2) can be located in the middle, not in the anterior part of the thorax of Brachiosaurus similar to a giraffe. In this context, it is interesting to note that the head volume of Brachiosaurus brancai in percentage of body mass was about 4 times smaller than that of a prosauropod such as Plateosaurus. A large mass located at the head would impose additional strains on Brachiosaurus since such a mass could have a large impact on the center of gravity, especially during moving. It remains to be tested whether this type of negative correlation between head volume and body mass truly exists in the lineages of herbivorous sauropods.

Besides the general body volume and surface determinations, we tested for the slim reconstruction of Brachiosaurus brancai whether the presumable dimensions of the major organs located in its thoracic cavity (lungs, gastrointestinal tract etc.), when taken together and summed up, are actually in the same order of magnitude to fit into the thoracic-abdonimal cavity, i.e. the anatomical limitations given by the skeleton according to our 3D reconstruction. As such, the integument, as a 
volume resp. mass factor, plays an essential part. We determined that $\sim 5 \%$ or $2,140 \mathrm{~kg}$ of the body mass of Brachiosaurus brancai had been represented by this organ, and solely $\sim 1,000 \mathrm{~kg}$ account for the thoracicabdominal cavity due the large surface area. Another major volume of the thorax is the lung. We determined by allometric scaling a lung volume of $\sim 2,9561$ and a lung mass of $376 \mathrm{~kg}$. But it has to be emphasized here that especially these lung volume and mass reconstructions remain questionable, mainly because compared with reptilian and avian lungs, those of mammals are very difficult to inflate since the lung-volume normalized compliance is at least one order of magnitude less than that of the stiffest lizard lung (Klein et al. 2003), Furthermore, there is currently an intensive research on the type of respiration in general and the extent of pneumatization, i.e. air sacks in dinosaurs (Perry 1989, 1992, 2003; Perry \& Reuter 1999; Wedel 2003, 2005; Perry \& Sander 2004; Erickson 2005; O'Connnor \& Claessens 2005). There are several potential benefits of a pulmonary air sac system, i.e. mass reduction, improved thermoregulation (heat evaporated into the air sacs and anatomical position of the air sacs between the skeletal muscle and viscera), and most importantly, efficient lung ventilation and gas exchange. It seems close at hand that such anatomical features in sauropods must have played a crucial role in the overall evolutionary trend in sauropods towards gigantism. Insofar we would share the opinion by Wedel (2003) and Perry \& Sander (2004) that rather than being an aberrant feature solely related to mass reduction, the postcranial pneumaticity of sauropods may be one key to understanding their physiology and paleobiology, in particular the fast growth rates in sauropods which at sexual maturity were already gigantic but continued to increase in size as adults (Sander 2000; Sander \& Tückmantel 2003). Recent published growth curves for Tyrannosaurus by Erickson et al. (2005) and similar studies on Sauropodamorpha by Sander (2000), and Tütgen et al. (2004) on Sauropodomorpha and on a prosauropod dinosaur by Sander \& Klein (2005) revealed an acceleration in growth rates up to fourfold (Tyrannosaurus), indicating that, with respect to body size, some dinosaurs grew more rapidly than living reptiles (Erickson 2005). These rapid growth patterns were followed periodically by temporary slow-downs or cessations of growth (Reid 1997).

Another major volume factor in the thoracic cavity is the gastrointestinal tract. According to Owen-Smith (1988) and his studies on megaherbivores the capacity of this organ should increase in direct proportion to body mass, in the absence of any adaptive trend. Very recently Clauss et al. (2005) tested the predictions on body mass and gut contents in a dissected African elephant. They could confirm this assumption by OwenSmith who found a remarkable uniformity of the body mass-gastrointestinal tract relationship among, at least, mammals. When we applied those allometric formulas on Brachiosaurus brancai we estimated a gut mass of $22,480 \mathrm{~kg}$. If we intend to make an organ system integration of the different organs into the thoracicabdominal cavity of Brachiosauris brancai, then, as for the lung, the volume, i.e. the actual gut capacity, is quite more important than any prediction on the mass. Here, according to Calder (1996) it can be assumed that the full-gut capacity is usually approximately 3.4 times higher than the mass, i.e. $\sim 8,430 \mathrm{~kg}$. For the remaining organs and organ systems of Brachiosaurus brancai we assumed the following volumes for the thoracic-abdominal cavity: $4,275 \mathrm{~kg}$ (muscle mass, $1 / 4$ of total muscle mass), $1,850 \mathrm{~kg}$ (skeleton, $1 / 3$ of the total mass), $1,410 \mathrm{~kg}$ (blood volume, $3 / 4$ of the total blood volume), $\sim 55 \mathrm{~kg}$ (kidneys), $\sim 200 \mathrm{~kg}$ (heart), $\sim 318 \mathrm{~kg}$ liver, and $141 \mathrm{~kg}$ spleen. Surprisingly, taken together, this sums up to a total volume of about $\sim 20 \mathrm{~m}^{3}$, which would be, clearly, in the order of magnitude given by the anatomical limitations given by the skeleton, i.e. approx. $32 \mathrm{~m}^{3}$. One might speculate whether the difference found after organ system integration into the anatomical limits given by the skeleton indicate that the presumable dimensions of the lung and/or the gut are actually too low for Brachiosaurus brancai. In case of the lung, one might speculate whether this currently not specified volume might indicate the existence of large air sacs in the thoracic-abdominal cavity. In future, based on these allometric data, it should be possible to "implant" with advanced software programs the reconstructed organs into an artificial 3D organism to visualize an organ system integration. Finally, although the main purpose of the reconstruction of the major organs by allometric functions was to test whether they actually might fit into the anatomical limitations given by the skeleton, especially the metabolic data ask for a stable environment and a nutritionally rich flora. Even minor changes in the environment causing a shortness in nutritional components, particularly in fast growing juvenile organisms, would have been catastrophic to these giant herbivorous organisms.

\section{Acknowledgements}

We thank all the members of the DFG (Deutsche Forschungsgemeinschaft) Research Unit 533 "Biology of the Sauropod Dinosaurs: The Evolution of Gigantism". Further thanks go to the staff of the Museum für Naturkunde der Humboldt-Universität zu Berlin where we measured the skeleton, especially for their warm response, patience and support. The project has been granted financial support from the DFG-GU 414/3-1. We thank two anonymous reviewers for reading the manuscript.

\section{References}

Anderson, J. F., Hall-Martin, A. \& Russell, D. A. 1985. Long-bone circumference and weight in mammals, birds, and dinosaurs. Journal Zoology 207: 53-61.

Anderson, J. F., Rahn, H. \& Prange, H. D. 1979. Scaling of supportive tissue mass. - The quarterly review of biology 54: 139-148. 
Bronstein, I. N. \& Semendjajew K. A. 1985. Taschenbuch der Mathematik. Verlag Deutsch, Thun.

Calder, W. A. 1984. Size, function, and life history. Harvard University Press Cambridge, Massachusetts.

Calder, W. A. 1996. Size, function, and life history. Harvard University Press Cambridge, Massachusetts.

Caroll, R. L. 1993. Paläontologie und Evolution der Wirbeltiere. Georg Thieme Verlag, Stuttgart, New York.

Christiansen, P. \& Fariña, R. A. 2004. Mass prediction in theropod dinosaurs. - Journal of Paleobiology 16: 85-92.

Clauss, M., Robert, N., Walzer, C., Vitaud, C. \& Hummel, J. 2005. Testing predictions on body mass and gut contents: dissection of an African elephant Loxodonta Africana Blumenbach 1797. European Journal of Wildlife Research 51: 291-294.

Colbert, E. H. 1962. The weights of dinosaurs. - American Museum Novitates 2076: 1-16.

Erickson, G. M. 2005. Assessing dinosaur growth patterns: a microscopic revolution. - Trends in Ecology and Evolution 20 (12): 677-684.

Gunga, H.-C., Kirsch, K., Baartz, F., Röcker, L., Heinrich, W.-D., Lisowski, W., Wiedemann, A. \& Albertz, J. 1995. New data on the dimensions of Brachiosaurus brancai and their physiological implications. - Naturwissenschaften 82: 190-192.

Gunga, H.-C., Kirsch, K., Rittweger, J., Clarke, A., Albertz, J., Wiedemann, A., Mokry, S., Suthau, T., Wehr, A., Clarke, D., Heinrich, W.-D. \& Schultze, H.-P. 1999. Body size and body volume distribution in two sauropods from the Upper Jurassic of Tendaguru/ Tansania (East Africa). - Mitteilungen aus dem Museum für Naturkunde in Berlin, Geowissenschaftliche Reihe 2: 91-102.

Gunga, H.-C., Suthau, T., Bellmann, A., Friedrich, A., Schwanebeck, T., Stoinski, S., Trippel, T., Kirsch, K., \& Hellwich, O. 2007. Body mass estimations for Plateosaurus engelhardti using laser scanning and 3D reconstruction methods. - Naturwissenschaften 94: $623-630$

Haubold, H. 1990. Die Dinosaurier. System, Evolution, Paläobiologie. (4. Aufl.) A. Ziemsen Verlag, Wittenberg.

Henderson, D. M. 1999. Estimating the masses and centers of masses of extinct animals by 3-D mathematical slicing. - Paleobiology 25: $88-106$.

Janensch, W. 1914. Bericht über den Verlauf der Tendaguru-Expedition. - Archiv für Biontologie III (1): 15-58.

Janensch, W. 1950. Die Wirbelsäule von Brachiosaurus brancai. Palaeontographica, Supplement 7 (1, Teil 3): 27-92.

Klein, W., Abe, A. S. \& Perry, S. F. 2003. Static lung compliance and body pressures in Tupinambis merianae with and without posthepatic septum. - Respiratory Physiology and Neurobiology 135: 73-86.

Lambert, D. 1980. A field guide to dinosaurs. Avon, New York.

Motani, R. 2001. Estimating body mass from silhouettes: testing the assumption of elliptical body cross-sections. - Paleobiology 27: 735-750.

O'Connor, P. M. \& Claessens, L. P. A. M. 2005. Basic avian pulmonary design and flow-through ventilation in non-avian theropod dinosaurs. - Nature 436 (7048): 253-256.
Owen-Smith, R. N. 1988. Megaherbivores. The influence of very large body size on ecology. Cambridge University Press, Cambridge.

Peczkis, J. 1994. Implications of body-mass estimates for dinosaurs. Journal of Vertebrate Paleontology 14: 520-533.

Perry, S. F. 1989. Mainstreams in the evolution of vertebrate respiratory structures. - Form and Function in Birds 4: 1-67.

Perry, S. F. 1992. Gas exchange strategies in reptiles and the origin of the avian lung. In Wood, S. C., Weber, R. E., Hargens, A. R. \& Millard, R. W. (eds). Physiological Adaptations in Vertebrates. Marcel Dekker Inc., New York, Basel, Hong Kong: pp. 149-167.

Perry, S. F. 2003. Cross-current exchange as the key to the origin of gigantism and of birds in saurischian dinosaurs. In Proceedings of the Satellite Symposium on Respiratory Physiology and Neurobiology. Celebration of Peter Scheid's Career, San Diego: p. 5 .

Perry, S. F. \& Reuter, C. 1999. Hypothetical lung structure of $\mathrm{Bra}_{-}$ chiosaurus (Dinosauria; Sauropoda) based on functional constraints. - Mitteilungen aus dem Museum für Naturkunde in Berlin, Geowissenschaftliche Reihe 2: 75-79.

Perry, S. F. \& Sander, M. 2004. Reconstructing the evolution of the respiratory apparatus in tetrapods. - Respiratory Physiology \& Neurobiology 144 (2-3): 125-139.

Reid, R. E. H. 1997. How dinosaurs grew. In Farlow, J. O. \& BrettSurman, M. K. (eds). The complete dinosaurs. Indiana University Press: pp. 403-419.

Sander, P. M. 2000. Longbone histology of the Tendaguru sauropods: implications for growth and biology. - Paleobiology 26 (3): $466-$ 488.

Sander, P. M. \& Klein, N. 2005. Developmental plasticity in the life history of a prosaurod dinosaur. - Science 310: 1800-1802.

Sander, P. M. \& Tückmantel, C. 2003. Bone lamina thickness, bone apposition rates, and age estimates in sauropod humeri and femora. - Paläontologische Zeitschrift 77 (1): 161-172.

Schmidt-Nielsen, K. 1997. Animal Physiology. Cambridge University Press, Cambridge.

Schmidt-Nielsen, K. 1984. Scaling: Why is animal size so important? Cambridge University Press, Cambridge.

Seebacher, F. 2001. A new method to calculate allometric length-mass relationships of dinosaurs. - Journal of Vertebrate Paleontology 21: $51-60$.

Tütgen, T., Pfretzschner, H.-U., Vennemann, T. W., Sun, G. \& Wang, Y. D. 2004. Palaeobiology and skeletochronology of Jurassic dinosaurs: implications from the histology and oxygen isotope compositions of bones. - Palaeogeography Palaeoclimatology Palaeoecology 206: 217-238.

Wedel, M. J. 2003. Vertebral pneumaticity, air sacs, and the physiology of sauropod dinosaurs. - Paleobiology 29 (2): 243-255.

Wedel, M. J. 2005. Postcranial skeletal pneumaticity in sauropods and its implications for mass estimates. In Wilson, J. A. \& Curry-Rogers, K. (eds). The Sauropods: Evolution and Paleobiology. University of California Press: pp. 201-228.

Withers, P. C. 1992. Comparative animal physiology. Saunders College Publishing, Fort Worth 